\title{
Driving factors of carbon emissions in China's municipalities: a LMDI approach
}

\author{
Yuanxin Liu ${ }^{1,2} \cdot$ Yajing Jiang $^{1} \cdot$ Hui Liu ${ }^{3} \cdot$ Bo Li $^{3} \cdot$ Jiahai Yuan $^{1,2}$ (I) \\ Received: 12 May 2021 / Accepted: 26 October 2021 / Published online: 12 November 2021 \\ (c) The Author(s), under exclusive licence to Springer-Verlag GmbH Germany, part of Springer Nature 2021
}

\begin{abstract}
China, as the world's largest carbon dioxide emitter, is bound to assume the important responsibility of energy conservation and emission reduction. To this end, each city, led by representative municipalities, must enhance efforts in carbon emission reduction to jointly realize China's low-carbon transition. Taking four representative municipalities, namely, Beijing, Tianjin, Shanghai, and Chongqing as the case cities, this paper establishes a decomposition analysis for the driving factors of carbon emissions by applying the LMDI method covering data from 2007 to 2017 . Kaya identity is used to decompose the effects into eight driving factors: GDP effect, industrial structure effect, energy intensity effect, overall energy structure effect, population effect, urbanization effect, per capita energy consumption effect, urban and rural energy structure effect. The results show that at the municipality level, the driving factors that contribute to carbon emissions are the GDP growth effect and the population effect, with the former still being the most important factor in the municipalities with faster economic growth; and industrial structure effect is the most important factor that inhibits carbon emissions, followed by energy structure effect. This paper considers the driving factors of both the production side and the residential consumption side from the city level. The research reveals the main driving factors that effect the carbon emissions of megacities in developing countries, and highlights the leading role of megacities in terms of carbon emission reduction in China and even the world. The paper thereby puts forward policy implications for China's economic policies.
\end{abstract}

Keywords Carbon emissions · Driving factors $\cdot$ LMDI $\cdot$ Four municipalities $\cdot$ China

Highlights

- Decompose and analyze the driving factors of carbon emissions in megacities of China.

- Quantify and discuss energy-related carbon emissions of municipalities.

- Show the differential impact of all driving factors on carbon emissions.

- GDP effect and population effect are the most important driving factors to increases.

- The industrial structure effect is the main driving factor to reduce carbon emissions.

\section{Responsible Editor: Ilhan Ozturk}

Jiahai Yuan

yuanjh126@126.com

1 School of Economics and Management, North China Electric Power University, Beijing 102206, China

2 Beijing Key Laboratory of New Energy and Low-Carbon Development (North China Electric Power University), Beijing 102206, China

3 School of Foreign Languages, North China Electric Power University, Beijing 102206, China

\section{Introduction}

Global warming is one of the major environmental problems facing human society and the large amount of carbon dioxide produced by burning fossil energy is the main reason for it. In recent years, with the continuous economic development, China's energy consumption has continued to grow rapidly, which has not only aggravated the energy crisis, but also raised the level of carbon emissions. Having become the largest energy consumer and carbon emitter in the world, China is required to assume the responsibility for carbon emission reduction regardless of external environmental pressure or internal development needs. Therefore, the promotion of energy conservation, emission reduction, and a low-carbon economy will not only help solve domestic energy and environmental problems, but also promote global emission reductions and ease international pressure. To fulfill its responsibility as a major country and make its contribution to addressing global climate change, China has set a goal of peaking carbon 
Table 1 Key policies for China's energy development

\begin{tabular}{|c|c|c|c|}
\hline Policy document & Year of release & Target year & Content \\
\hline China's Agenda 21 & 1994 & - & $\begin{array}{l}\text { Putting forward the strategy of sustainable development } \\
\text { and implementing the policy of putting equal emphasis } \\
\text { on development and economy. }\end{array}$ \\
\hline $\begin{array}{l}\text { Renewable Energy Law of the People's Republic of } \\
\text { China }\end{array}$ & 2006 & - & $\begin{array}{l}\text { Strengthening guidance and support for the development } \\
\text { of renewable energy and promoting large-scale devel- } \\
\text { opment and utilization of clean renewable energy. }\end{array}$ \\
\hline China's National Climate Change Programme & 2007 & 2010 & $\begin{array}{l}\text { By } 2010 \text {, China's energy consumption per unit of GDP } \\
\text { will be about } 20 \% \text { lower than that in } 2005 \text {. Carbon } \\
\text { dioxide emissions will be reduced and the proportion } \\
\text { of the total amount of renewable energy development } \\
\text { and utilization (including hydropower) in the primary } \\
\text { energy supply structure will be increased to about } 10 \% \text {. }\end{array}$ \\
\hline The Twelfth Five-Year Plan for Energy Development & 2013 & 2015 & $\begin{array}{l}\text { Controlling both energy consumption intensity and total } \\
\text { consumption, with } 4 \text { billion tons of standard coal, and } \\
\text { energy consumption per unit of GDP falling } 16 \% \text { from } \\
\text { 2010; improving overall energy efficiency to } 38 \% \text {; } \\
\text { carbon dioxide emissions per unit of GDP falling } 17 \% \\
\text { from } 2010 \text {. }\end{array}$ \\
\hline Air Pollution Prevention and Control Action Plan & 2013 & 2017 & $\begin{array}{l}\text { Reducing the emission of pollutants by adjusting the } \\
\text { industrial structure, promoting cleaner production, and } \\
\text { encouraging energy conservation. }\end{array}$ \\
\hline The 13th Five-Year Plan for Energy Development & 2017 & 2020 & $\begin{array}{l}\text { By } 2020 \text {, the total energy consumption will be controlled } \\
\text { within } 5 \text { billion tons of standard coal, with energy con- } \\
\text { sumption per unit GDP falling by } 15 \% \text { compared with } \\
2015 \text { and carbon dioxide emissions per unit GDP fall- } \\
\text { ing by } 18 \% \text { compared with } 2015 \text {; adjusting the energy } \\
\text { structure, increasing the proportion of non-fossil energy } \\
\text { consumption to more than } 15 \% \text {, striving to reach } 10 \% \\
\text { of natural gas consumption, and reducing the propor- } \\
\text { tion of coal consumption to less than } 58 \% \text {. }\end{array}$ \\
\hline $\begin{array}{l}\text { Energy Supply and Consumption Revolution Strat- } \\
\text { egy(2016-2030) }\end{array}$ & 2016 & 2030 & $\begin{array}{l}\text { By } 2030 \text {, the total energy consumption will be controlled } \\
\text { within } 6 \text { billion tons of standard coal, and the propor- } \\
\text { tion of non-fossil energy in total energy consumption } \\
\text { will reach about } 20 \% \text {; carbon dioxide emissions per } \\
\text { unit of GDP will fall } 60 \%-65 \% \text { from } 2005 \text {, and carbon } \\
\text { dioxide emissions will peak no later than } 2030 \text {. }\end{array}$ \\
\hline Three-Year Action Plan for Cleaner Air & 2018 & 2020 & $\begin{array}{l}\text { The total coal consumption will decrease by } 10 \% \text { com- } \\
\text { pared with } 2015 \text { in the five provinces (municipalities) } \\
\text { of Beijing, Tianjin, Hebei, Shandong, and Henan, and } \\
\text { by } 5 \% \text { in the Yangtze River Delta, and achieve a nega- } \\
\text { tive growth in Fenwei Plain. }\end{array}$ \\
\hline
\end{tabular}

dioxide emissions by 2030 and achieving carbon neutrality by 2060 .

For a long time, the resource endowment of being "rich in coal, poor in oil and little in gas" has determined China's coal-based energy structure. To prevent the further deterioration of global warming and solve domestic energy and environmental problems caused by economic development, the Chinese government has promulgated several energy development policies since the first mentioning of carbon emission reduction policies in 2007, as shown in Table 1. It aims to promote the sustainable development of the economy, energy, and the environment by reducing energy consumption and carbon emission. According to actual statistics, "China's National Climate Change Program (June 2007)" set the goal of "reducing China's energy consumption per unit GDP by about 20\% in 2010 compared to 2005". In 2010, China's energy consumption per unit GDP was 0.875 tons of standard coal per 10,000 yuan, a decrease of $37 \%$ from 2005, 17 percentage points higher than that of the target. In addition, in 2015, China's total energy consumption was 4.3 billion tons of standard coal, energy consumption per unit of GDP 0.624 tons of standard coal per 10,000 yuan, and carbon dioxide emissions per unit of GDP 0.013 tons per 10,000 yuan. According to the "Twelfth Five-Year Plan for Energy Development", although the total control target was not achieved, the energy consumption per unit of GDP fell by $29 \%$ compared with $2010,13 \%$ above the target, and the carbon dioxide emissions per unit of GDP fell by $33 \%$ 
compared with 2010 , which exceeded the target by $16 \%$. In 2019, China's energy consumption per unit of GDP was 0.490 tons of standard coal per 10,000 yuan, down $21.4 \%$ from 2015, and carbon dioxide emissions per unit of GDP was 0.010 tons per 10,000 yuan, down $25.6 \%$ from 2015 and $48.5 \%$ from 2005 , which completed the target that "the carbon intensity in 2020 will be reduced by $40 \%-45 \%$ compared to 2005" ahead of schedule. This shows that China's "topdown" energy policy has played a positive role in reducing energy consumption and curbing the growth of carbon emissions.

China is the largest carbon emitter in the world. Its carbon emission reduction is not only closely related to countries around the world but also vital to its own development. At present, reducing carbon emissions in China is one of the research focuses of many scholars. By now, several studies have analyzed the driving forces of carbon emissions at the national, regional, provincial and city levels. For example, at the national level, Guan et al. (2008) decomposed carbon emissions into five driving forces, population, emission intensity, economic production structure, consumption pattern, and per capita consumption volume, and found that GDP growth and production structure were the main factors contributing to the increase in China's carbon dioxide emissions, and the improvement in efficiency only reduced part of the emissions. Wang et al. (2018) compared the decoupling relationship between economic development and $\mathrm{CO} 2$ emissions in China and the USA from 2000 to 2014 and found that both income and population effects promoted carbon emissions in China and the USA, while energy intensity effect and the energy structure effect limited the growth of carbon emissions. In addition, the carbon intensity effect had increased China's carbon emissions and curbed that of the USA. At the regional level, Gao et al. (2016) analyzed CO2 emissions of six east and south coastal provinces in China and found that economic development and energy efficiency were the two leading factors contributing positively and negatively to emission growth, respectively. At the provincial level, Ye et al. (2017) tried to analyze the energy-related $\mathrm{CO} 2$ emissions of 30 provinces in China and found that the energy industry was the largest sectoral contributor to the growth of carbon emissions in most provinces, while the service and household sectors had played an increasingly significant role in promoting provincial emissions. The key to reducing carbon emissions is to identify and analyze the key sectors for carbon reduction in each province. And at the city level, Xu et al. (2021) selected Chinese prefecturelevel cities as the research object and analyzed its data in 2005 and 2012. The final result showed that gross domestic product, research and development, direct foreign investment, and urban built-up area were major factors affecting $\mathrm{CO} 2$ emissions. These research conclusions generally show that economic development is the main factor driving the growth of carbon emissions, and economic structure and energy structure have great potential for emission reduction in China.

In addition, some articles focus on the role of certain driving factors based on previous studies. Wang et al. (2019) believes that a comprehensive understanding of the interdependence between China's economy and carbon emissions can better help China transit to a low-carbon economy, and can also provide references for other developing countries. Sun and Huang (2020) analyzes the correlation between the level of urbanization and carbon emission efficiency, and provides a theoretical reference for government decisionmakers in urban planning and the green economy. However, the influencing factors of carbon emissions are relatively complex, involving natural factors such as resource endowments and climate conditions, as well as social factors such as economic level, population size, industrial structure, and energy consumption intensity. Due to the limited factors in analyzing carbon emissions, the research results are often one-sided.

It is acknowledged that decomposition methods have been widely used to analyze carbon emissions and energy consumption. Commonly, the decomposition analysis mainly includes two methods, structural decomposition analysis (SDA) (Das and Paul 2014; Cansino et al. 2016) and index decomposition analysis (IDA) (Wang et al. 2019; Akbostanc1 et al. 2011). SDA is based on input-output data, whereas IDA uses departmental aggregate data. Compared with SDA, IDA has the advantages of simplicity and flexibility, and lower data requirements, and it comes from energy system analysis, which means that IDA has a closer relationship with energy system research (Wang et al. 2017). Therefore, many scholars apply the IDA method to the driving force analysis of energy. The LMDI method belongs to the IDA method, and Ang and Choi (1997) were the first to apply the LMDI method to analyze industrial carbon emissions. After that, more and more scholars began to decompose and analyze energy consumption and energy-related emission gases (Jeong and Kim 2013; Xu et al. 2014; Zhao et al. 2010). For example, Jeong and Kim, (2013) used the LMDI method to decompose the changes in $\mathrm{CO} 2$ emissions from the Korean industrial manufacturing sector into the impact of five different factors including overall industrial activity (activity effect), industrial activity mix (structure effect), sectoral energy intensity (intensity effect), sectoral energy mix (energy-mix effect), and $\mathrm{CO} 2$ emission factors (emission-factor effect), and found that the structure effect, intensity effect, and emission-factor effect played roles in reducing greenhouse gas emissions, and the energy-mix effect increased greenhouse gas emissions. In addition, structure effects play a greater role in reducing greenhouse gas emissions than intensity effects. Xu et al. (2014) analyzed the impact of five driving factors (energy structure, 
energy intensity, industry structure, economic output, and population-scale effects) on carbon emission for energy consumption in China, the result showed that the major driver of carbon emissions is the economic output effect, followed by population-scale and energy structure effects. The energy intensity effect is a main inhibitory factor. Wang et al. (2020) applied the LMDI decomposition technique extended by Kaya identity to identify and analyze the contribution of population, affluence, energy intensity, carbon intensity, and some other factors of the decoupling process. Their results implied that affluence level was the key offsetting effect of decoupling process, while energy intensity was the most significant effect to promote the decoupling process. All these researches illustrated the great advantages of the LMDI method in analyzing driving factors. Therefore, this paper adopts the LMDI method based on Kaya identity to analyze the driving factors of carbon emissions.

At present, China has made certain achievements in energy conservation and emission reduction. However, in the long run, under the severe situation of intensified climate change, deterioration of the ecological environment, and prominent contradictions of resource mismatches, the top priority should be understanding the driving factors of carbon emissions growth to successfully peak carbon dioxide emissions by 2030 and achieve carbon neutrality by 2060 . Based on the literature review, many scholars have studied China's carbon emission drivers from various aspects, but there is still a research gap. Most of these studies were launched either at the national or at the provincial level, and a few studies that take cities as the starting point select either a large number of cities as the research objects or only one city. Although most researches at the provinciallevel have also included the four cities involved in this study (Chen et al. 2019; Zhang et al. 2016), they mainly analyze from the overall or the classification of the provinces. The internal reasons for the driving factors of each city to affect the changes in carbon emissions have not been elaborated. In light of the huge size of China's economy and population, and the large differences in energy types and economic development levels between regions and cities, analyzing the driving factors of carbon emissions growth from an overall or individual level could only bring relatively one-sided experience and results. Therefore, the existing literature could provide little city-level energy-driven experience in developing countries.

The large cities in China are the main contributions of carbon dioxide emissions and the main driving force of growth, whose carbon emissions account for more than $5 \%$ of the total. This paper takes four super-large municipalities in China as the research objects and thoroughly researches the impact of different factors on carbon emissions from the city level, which is believed to fill the research gap. As municipalities, these four cities have unique political and economic status, and they also play a leading role in reducing carbon emissions in China and even internationally. Based on the previous research, we expand the driving factors to cover both the production side and the residential consumption side, to conduct a more detailed analysis of the changes in carbon emissions. The results not only give reference for other cities and the whole country to promote the energy-saving and emission reduction process but also provide countries around the world with the experience of large cities in developing countries. Moreover, existing studies have shown that the COVIID-19 pandemic caused a huge impact on global carbon emissions. When dealing with carbon emissions changes after the COVID-19 pandemic, it may be helpful to take a lesson from the 2008 global economic crisis (Wang et al. 2020; Wang et al. 2021). This study considers the driving factors of the four municipalities from 2007 to 2017, which will help to better understand the carbon emissions changes and their driving factors to avoid the rebound in carbon emissions in China.

The rest of the paper is organized as follows: Part 2 describes the data and methodology. Part 3 depicts the $\mathrm{CO} 2$ emissions situation in China and discusses the main decomposition results. Part 4 presents the conclusions and policy suggestions.

\section{Data and methodology}

\section{Data sources}

In this paper, four representative municipalities in China, namely Beijing, Tianjin, Shanghai, and Chongqing, were selected as the research subjects, and the data of them from 2007 to 2017 were chosen to analyze the driving factors of carbon emissions in them. Since 2007, when the policy of carbon reduction was first proposed by the Chinese government, the intensity of China's carbon emission has kept declining with the introduction and implementation of the new carbon reduction policy. Therefore, we can find the main carbon emission drivers of the municipalities in this period through temporal analysis.

The data used for this empirical study includes data on carbon emissions and energy consumption of different sectors in each municipality from the CEADS database (China carbon emission accounts databases) ${ }^{1}$, and data on GDP, population, and added value in different sectors from the National Bureau of Statistics of China. The eight different sectors are farming, forestry, livestock and fishing, industry, construction, transportation, wholesale, retail and accommodation, others, as well as resident-side towns and villages.

\footnotetext{
${ }^{1}$ Database website: http://www.ceads.net/data/
} 
To exclude the effect of inflation on GDP, this paper uses GDP Deflator Method to adjust the 2017 GDP and added value of sectors to the current price of 2007.

\section{Exponential decomposition method}

The idea of exponential decomposition is to decompose the variation of the explained variables into a combination of variations of different factors, and then determine the weight according to different decomposition methods to identify the contribution of each factor. In building factor-decomposition models, the common methods used are Laspeyres exponential method, IPAT model, Paasche, and AMDI decomposition method, which all have their advantages and disadvantages, but most of them cannot decompose multiple factors and are often followed by a large residual value after decomposition. At present, LMDI, one of the IDA exponential decomposition methods, is widely used in the study of carbon emissions, which can eliminate the unexplained residual term and deal with the " 0 " value problem in the data. It has the advantages of a simple calculation process and a clear decomposition result (Ang 2004). Based on these advantages and suitability for the research objects, the LMDI model can better and more effectively explore the research purpose of this paper.

The Kaya identity decomposes the influencing factors of carbon emissions into four factors: population scale, economic development level, energy intensity, and energy structure. The specific expression is shown in Eq. (1).

$C=P \times \frac{\mathrm{GDP}}{P} \times \frac{E}{\mathrm{GDP}} \times \frac{C}{E}$

$C$ denotes carbon dioxide emissions, $P$ denotes population scale, $E$ denotes energy consumption, and GDP denotes gross domestic product. As hinted by the previous studies, the changes in the total scale of carbon emissions are influenced by economic scale, industrial structure, energy intensity, energy structure, population size, urbanization level, and per capita energy consumption. Considering the inherent differences between economic and household sectors, the identity is broken down into two parts: economic sectors and residential sectors, as presented in Eq. (2). The carbon emissions of economic sectors are mainly determined by economy scale, industrial structure, energy intensity, and energy structure, while the resident-side urban-rural sectors are mainly affected by population size, urbanization, per capita energy consumption, and energy structure.

$C=\mathrm{GDP} \times \frac{\mathrm{GDP}_{\mathrm{i}}}{\mathrm{GDP}} \times \frac{E_{\mathrm{i}}}{\mathrm{GDP}_{\mathrm{i}}} \times \frac{E_{\mathrm{ij}}}{E_{\mathrm{i}}} \times \frac{C}{E_{\mathrm{ij}}}+P \times \frac{P_{i}}{\mathrm{P}} \times \frac{E_{i}}{P_{i}} \times \frac{E_{\mathrm{ij}}}{E_{\mathrm{i}}} \times \frac{C}{E_{\mathrm{ij}}}$

$i$ denotes sectors, $j$ denotes fuels, $\mathrm{GDP}_{\mathrm{i}}$ denotes carbon dioxide emissions of economic sector $i, P_{\mathrm{i}}$ denotes population scale of residential sector i, $E_{\mathrm{i}}$ denotes energy consumption of different sectors, $E_{\mathrm{ij}}$ denotes energy consumption of different fuels in different sectors.

Based on the extended kaya identity, this paper analyzes the driving factors of carbon dioxide emissions in six economic sectors and two residential sectors of the four representative municipalities by using the LMDI decomposition method and decomposes them into eight driving factors: GDP effect, industrial structure effect, energy intensity effect, total energy structure effect, population effect, urbanization effect, per capita energy consumption effect, urban and rural energy structure effect. The concrete expression is shown in Eq. (3):

$$
\begin{aligned}
C_{\mathrm{n}}(\mathrm{t}) & =\sum_{i=1}^{6} \sum_{j=1}^{J} Y^{n}(t) \frac{Y_{\mathrm{i}}^{n}(t)}{Y^{n}(t)} \frac{E_{\mathrm{i}}^{n}(t)}{Y_{i}^{n}(t)} \frac{E_{i j}^{n}(t)}{E_{i}^{n}(t)} \frac{C_{i j}^{n}(t)}{C_{i j}^{n}(t)} \\
& +\sum_{i=7}^{8} \sum_{j=1}^{J} P^{n}(t) \frac{P_{i}^{n}(t)}{P^{n}(t)} \frac{E_{i}^{n}(t)}{P_{i}^{n}(t)} \frac{E_{i j}^{n}(t)}{E_{i}^{n}(t)} \frac{C_{i j}^{n}(t)}{E_{i j}^{n}(t)}
\end{aligned}
$$

$C$ denotes carbon dioxide emissions, $Y$ denotes the gross domestic product of each municipality, $E$ denotes energy consumption, $P$ denotes population size, and according to the driving factors selected herein, formula (3) is reformulated as formula (4):

$$
\begin{aligned}
C_{\mathrm{n}}(\mathrm{t}) & =\sum_{i=1}^{6} \sum_{j=1}^{J} Y^{n}(t) G S_{i}^{n}(t) G E_{i}^{n}(t) G E S_{i j}^{n}(t) C I_{\mathrm{ij}}^{\mathrm{n}}(t) \\
& +\sum_{i=7}^{8} \sum_{j=1}^{J} P^{n}(t) U R_{i}^{n}(t) P E_{i}^{n}(t) P E S_{i j}^{n}(t) C C_{\mathrm{ij}}^{\mathrm{n}}(t)
\end{aligned}
$$

The meaning of the specific variables in Eqs. (3) and (4) is shown in Table 2.

Assuming the emission factors of fuels do not change with time, $C_{n}(t-1)$ and $C_{n}(t)$ are defined as carbon emissions from energy consumption at the primary and end of the period respectively, and then the effect of each factor on carbon emissions is expressed as formula (5) through decomposing with LMDI. The weighting factor is equal to the share of $\mathrm{CO} 2$ emissions caused by $\mathrm{j}$ fuel consumption in the i sector $C_{i j}^{n}\left(t^{*}\right)$ in the total provincial emissions $C_{n}\left(t^{*}\right)$ at the $t^{*}$ moment, and $t^{*} \in[t-1, t]$

$$
\begin{aligned}
\ln \frac{C_{\mathrm{n}}(\mathrm{t})}{C_{\mathrm{n}} \mathrm{t}(\mathrm{t})} & =\sum_{i=1}^{6} \sum_{j=1}^{J} C_{i j}^{n}\left(t^{*}\right) \\
C_{n}\left(t^{*}\right) & \ln \frac{Y^{n}(\mathrm{t})}{Y^{n}(\mathrm{t}-1)}+\ln \frac{G S_{i}^{n}(\mathrm{t})}{G S_{i}^{n}(\mathrm{t}-1)}+\ln \frac{G E_{i}^{n}(\mathrm{t})}{G E_{i}^{n}(\mathrm{t}-1)} \\
& \left.+\ln \frac{G E S_{i j}^{n}(\mathrm{t})}{G E S_{i j}^{n}(\mathrm{t}-1)}+\frac{C l_{i j}^{n}(\mathrm{t})}{C C_{i j}^{n}(\mathrm{t}-1)}\right]+\sum_{i=7}^{8} \sum_{j=1}^{J} \frac{C_{i j}^{n}\left(t^{*}\right)}{C_{n}\left(t^{*}\right)}\left[\ln \frac{P^{n}(\mathrm{t})}{P(\mathrm{t}-1)}\right. \\
& \left.+\ln \frac{U R_{i}^{n}(\mathrm{t})}{U R_{i}^{n}(\mathrm{t}-1)}+\ln \frac{P E_{i}^{n}(\mathrm{t})}{P E_{i}^{n}(\mathrm{t}-1)}+\ln \frac{P E S_{i j}^{n}(\mathrm{t})}{P E S_{i j}^{n}(\mathrm{t}-1)}+\frac{C I_{i j}^{n}(\mathrm{t})}{C \prod_{i j}^{n}(\mathrm{t}-1)}\right]
\end{aligned}
$$

In addition, in this paper, the logarithmic function is used to calculate the weight factor $\frac{C_{i j}^{n}\left(t^{*}\right)}{C_{n}\left(t^{*}\right)}$, as shown in formula (6):

$$
\frac{C_{i j}^{n}\left(t^{*}\right)}{C_{\mathrm{n}}\left(t^{*}\right)}=\frac{\left[C_{i j}^{n}(t)-C_{i j}^{n}(t-1)\right] /\left[\ln C_{i j}^{n}(t)-\ln C_{i j}^{n}(t-1)\right]}{\left[C_{n}(t)-C_{n}(t-1)\right] /\left[\ln C_{\mathrm{n}}(\mathrm{t})-\ln C_{\mathrm{n}}(t-1)\right]}
$$


Table 2 Meaning of variables in LMDI model

\begin{tabular}{ll}
\hline Variable & Meaning \\
\hline$t$ & Year of data used in calculations \\
$n$ & Code of municipality, $n=1,2,3,4$ \\
$i$ & Serial number of sectors \\
$j$ & Serial number of fuels \\
$C_{\mathrm{n}}$ & Total carbon emissions of municipality $\mathrm{n}$ \\
$C_{i j}^{n}$ & Carbon emissions of fuel $\mathrm{j}$ of sector $\mathrm{i}$ in municipality $\mathrm{n}$ \\
$Y^{\mathrm{n}}$ & GDP of municipality $\mathrm{n}$ \\
$Y_{\mathrm{i}}^{\mathrm{n}}$ & Added-value of sector i in municipality $\mathrm{n}$ \\
$P^{\mathrm{n}}$ & Total population of municipality $\mathrm{n}$ \\
$P_{\mathrm{i}}^{\mathrm{n}}$ & Urban or rural population in municipality $\mathrm{n}$ \\
$E_{\mathrm{i}}^{\mathrm{n}}$ & Total energy consumption of sector $\mathrm{i}$ in municipality $\mathrm{n}$ \\
$E_{\mathrm{ij}}^{\mathrm{n}}$ & Fuel $\mathrm{j}$ consumption of sector i in municipality $\mathrm{n}$ \\
$G S_{\mathrm{i}}^{\mathrm{n}}$ & Share of the added value of sector $\mathrm{i}$ out of total GDP in municipality $\mathrm{n}$ \\
$U R_{\mathrm{i}}^{\mathrm{n}}$ & Share of the urban or rural population in the total population of municipality $\mathrm{n}$ \\
$G E_{\mathrm{i}}^{\mathrm{n}}$ & Energy consumed per unit of the added value generated by sector $\mathrm{i}$ in municipality $\mathrm{n}$ \\
$G E S_{\mathrm{ij}}^{\mathrm{n}}$ & The proportion of fuel $\mathrm{j}$ consumption in total energy consumption of sector $\mathrm{i}$ in municipality $\mathrm{n}$ \\
$P E_{\mathrm{i}}^{\mathrm{n}}$ & Energy consumed per capita of sector $\mathrm{i}$ in municipality $\mathrm{n}$ \\
$P E S_{\mathrm{ij}}^{\mathrm{n}}$ & The proportion of fuel $\mathrm{j}$ consumption in urban and rural areas in municipality $\mathrm{n}$ \\
$C I_{\mathrm{ij}}^{\mathrm{n}}$ & Sector emission coefficient for fuel $\mathrm{j}$ in sector $\mathrm{i}$ in province $\mathrm{n}$ \\
\hline
\end{tabular}

Compared with the previous studies, the innovation of this paper is to apply the existing methods to new research objects and analyze the driving factors of carbon emissions in megacities. At the same time, the factors to be studied are expanded to cover both the production side and the resident side for a more detailed analysis.

\section{Empirical analysis}

\section{Analysis of carbon emissions characteristics of each municipality}

Overall, China's GDP grew from 27.94 trillion yuan in 2007 to 84.58 trillion yuan in 2017 , an increase of $203 \%$, while the total amount of carbon emissions in the whole society increased from 6.822 billion tons to 9.867 billion tons, an increase of $44.63 \%$ (National Bureau of Statistics 2020; Shan et al. 2020). The data shows that the growth of carbon emissions is much lower than that of GDP, which demonstrates that China, led by various carbon reduction policies, has managed to curb the growth of carbon emissions during its economic development.

From the municipal level, the changes in GDP and carbon emissions in each municipality during 2007-2017 are shown in Figure 1 and Figure 2.

The data show that the growth of GDP in all municipalities far outpaced that of carbon emissions, especially in Beijing, where total carbon emissions decreased by $17 \%$ over the decade mainly because of its unique location as the political and economic center of China. The introduction and strict implementation of policies such as moving out or shutting down local energy-consuming and polluting industries and reducing coal consumption for power generation and heating have resulted in decreased coal consumption from 17.17 million tons in 2007 to 2.68 million tons in 2017. As a result, carbon emissions have been curbed and Beijing has become the largest carbon emission reduction contributor compared with other municipalities. Most of the policies are made from the energy consumption structure. A considerable number of scholars have affirmed the impact of energy consumption structure on carbon emission intensity, indicating that the clean energy consumption structure plays a positive role in carbon emission reduction (Xia et al. 2021; Sun and Ren 2021).

In the four municipalities studied in this paper, carbon emissions fell after a peak over the decade, as shown in Table 3: the carbon emissions of Beijing reached a peak of 103 million tons in 2010; in Tianjin and Chongqing, peaks of 158 million tons and 164.8 million tons were reached in 2012, and the carbon emissions of Shanghai reached a peak of 201.2 million tons in 2013. It can be seen that the peak times of carbon emissions are mainly concentrated in the Eleventh Five-Year Plan (2006-2010) and the Twelfth Five-Year Plan (2011-2015) periods. The total carbon emissions of each municipality have declined in varying degrees through adjusting the industrial structure, promoting renewable energy, and encouraging energy conservation.

In the four municipalities directly under the Central Government, Shanghai has always ranked first in carbon 
Fig. 1 Changes in GDP of each municipality from 2007 to 2017
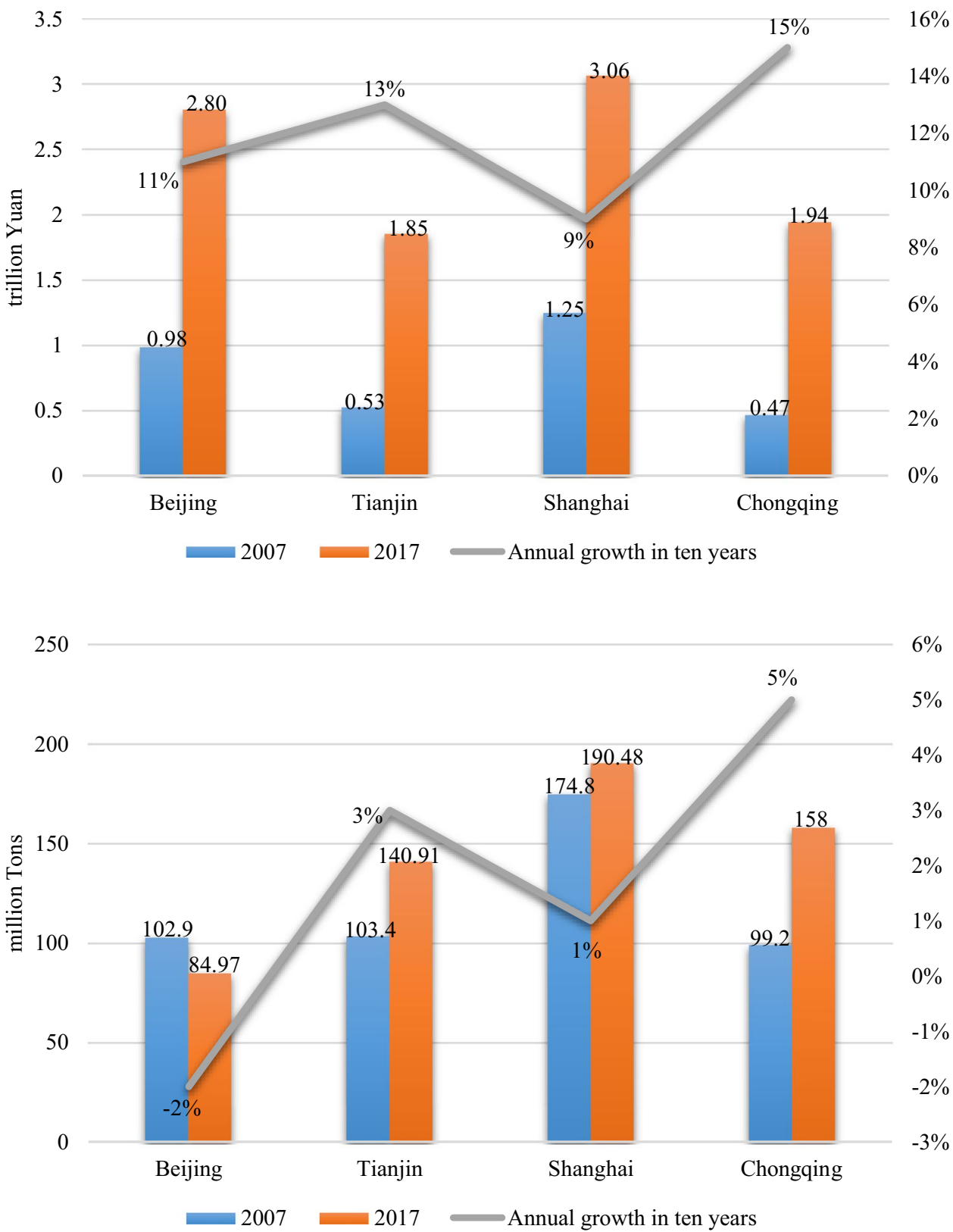

Fig. 2 Changes in carbon emissions of each municipality from 2007 to 2017
Table 3 Peaks and peak times of carbon emissions in each municipality

\begin{tabular}{lll}
\hline Municipality & $\begin{array}{l}\text { Peaks of carbon emissions/mil- } \\
\text { lion tons }\end{array}$ & Peak time \\
\hline Beijing & 103 & 2010 \\
Tianjin & 158 & 2012 \\
Shanghai & 201.2 & 2013 \\
Chongqing & 164.8 & 2012 \\
\hline
\end{tabular}

emissions, followed by Chongqing, which is mainly due to Shanghai's unique economic status and industrial structure. Li et al. (2021) show that there is a long-term equilibrium relationship between the intensity of carbon emissions and the three factors of energy consumption structure, energy intensity, and industrial structure. The three driving factors can be arranged according to their importance as follows: industrial structure, energy consumption structure, and energy intensity. As the economic center of China, Shanghai is characterized by rapid industrialization and urbanization with the advantage of various resources. Therefore, industry and transportation are the main carbon emission sources of Shanghai, which account for more than $80 \%$ of the total emissions. In addition, the main energy consumption products in Shanghai are coal and oil products, accounting for more than $75 \%$ of the total. As a result, an energy consumption structure dominated by coal and petroleum 
Table 4 Carbon emission intensity per unit of GDP in each municipality

\begin{tabular}{llll}
\hline Municipality & $\begin{array}{l}\text { Year 2007-ton/ per } \\
10,000 \text { yuan }\end{array}$ & $\begin{array}{l}\text { Year 2017-ton/ per } \\
10,000 \text { yuan }\end{array}$ & Trend \\
\hline Beijing & 1.045 & 0.303 & $-71.0 \%$ \\
Tianjin & 1.968 & 0.760 & $-61.4 \%$ \\
Shanghai & 1.399 & 0.622 & $-55.6 \%$ \\
Chongqing & 2.121 & 0.813 & $-61.7 \%$ \\
\hline
\end{tabular}

resources is formed. Chongqing, as an old industrial base and an important modern manufacturing base, is characterized by an unbalanced energy consumption structure for a long time, with coal as the main energy, and natural gas, oil, and electricity as the auxiliary ones, resulting in high carbon emissions. Although coal is still the main source of energy consumption in Beijing and Tianjin, the development of high-pollution and energy-consuming industries is strictly controlled and energy-saving and environment-friendly new energy sources are developed in these two cities. In addition, the proportion of natural gas consumption, which is featured by fewer carbon emissions, is higher in Beijing and Tianjin than that in Shanghai and Chongqing.

The carbon emission intensity per unit of GDP is one of the important indicators to measure the changing trend of the industrial structure and energy structure (Wang et al. 2020). In terms of carbon intensity per unit of GDP, China's carbon intensity per unit of GDP decreased from 2.44 tons per10,000 yuan to 1.17 tons per10,000 yuan from 2007 to 2017, a decrease of 52\%. Moreover, significant declines can be seen in all provinces, as shown in Table 4. Among them, Beijing's carbon emission intensity per unit of GDP reduced by $71.0 \%$, which is the largest, mainly because Beijing has promoted energy conservation and consumption reduction and optimized energy structure to reduce coal use. What's more, it also developed natural gas and other clean energy sources for power generation and heating, making clean energy more reasonably and efficiently used. Compared with the $\mathrm{CO} 2$ emissions per unit of GDP, each municipality's carbon intensity per unit of GDP is at a lower level, and the decrease is greater than the overall number, which is due to its reasonable industrial structure with a higher proportion of tertiary industry and manufacturing industry. The differences in carbon emission intensity per unit of GDP among municipalities are small, with Chongqing having the highest amount of 2.121 tons per10,000 yuan and Beijing the lowest amount of 0.303 tons per 10,000 yuan.

In terms of carbon emissions per capita, the number has always been high in China. In 2017, China's carbon emissions per capita were 0.32 tons per person, higher than the global average of 0.26 tons per person. This is mainly because there is a large amount of low-efficiency and highemission coal burned in a scattered way at the residential side of China, thus increasing per capita carbon emissions. Therefore, the per capita carbon emissions of each municipality, calculated by dividing the carbon emissions at the residential side by the population, are distinguished from that calculated by dividing the carbon emissions of the whole society by population. As shown in Table 5, in 2017, carbon emissions per capita in Beijing, Tianjin, Shanghai, and Chongqing were 0.77 tons per person, 0.55 tons per person, 0.54 tons per person, and 0.30 tons per person respectively. Although Beijing is the only one of the four municipalities that have decreased carbon emissions, its per capita carbon emissions is the highest due to its high urbanization level and high energy consumption per capita caused by winter heating. The figure shows that carbon emissions per capita in the northern provinces are higher than those in the southern ones, which is due to the differences caused by winter heating. Comparing Table 4 and Table 5, we can see that Chongqing and Shanghai have high carbon emissions intensity per unit of GDP and low carbon emissions per capita, while Beijing is the opposite.

To sum up, the carbon emissions of the four municipalities selected in this paper mainly have the following characteristics: (1) The carbon emissions of each municipality have reached the peak and show the trend of overall decline; (2) The carbon emission intensity per unit of GDP in each municipality has decreased greatly, and is ahead of the national average level; (3) The carbon emission intensity per capita of each municipality is generally higher than that of the whole country except Chongqing, and it is greatly affected by regional distribution and urbanization.
Table 5 Carbon emissions per capita of each municipality in 2017

\begin{tabular}{llll}
\hline Municipality & $\begin{array}{l}\text { Resident-side carbon emis- } \\
\text { sions-million tons }\end{array}$ & Population-10,000 & $\begin{array}{l}\text { Carbon emissions } \\
\text { per capita-ton per } \\
\text { person }\end{array}$ \\
\hline Beijing & 16.62 & 2171 & 0.77 \\
Tianjin & 8.49 & 1557 & 0.55 \\
Shanghai & 13.06 & 2418 & 0.54 \\
Chongqing & 9.08 & 3075 & 0.30 \\
\hline
\end{tabular}


Fig. 3 Contribution of driving factors of carbon emissions in each municipality during 2007-2017

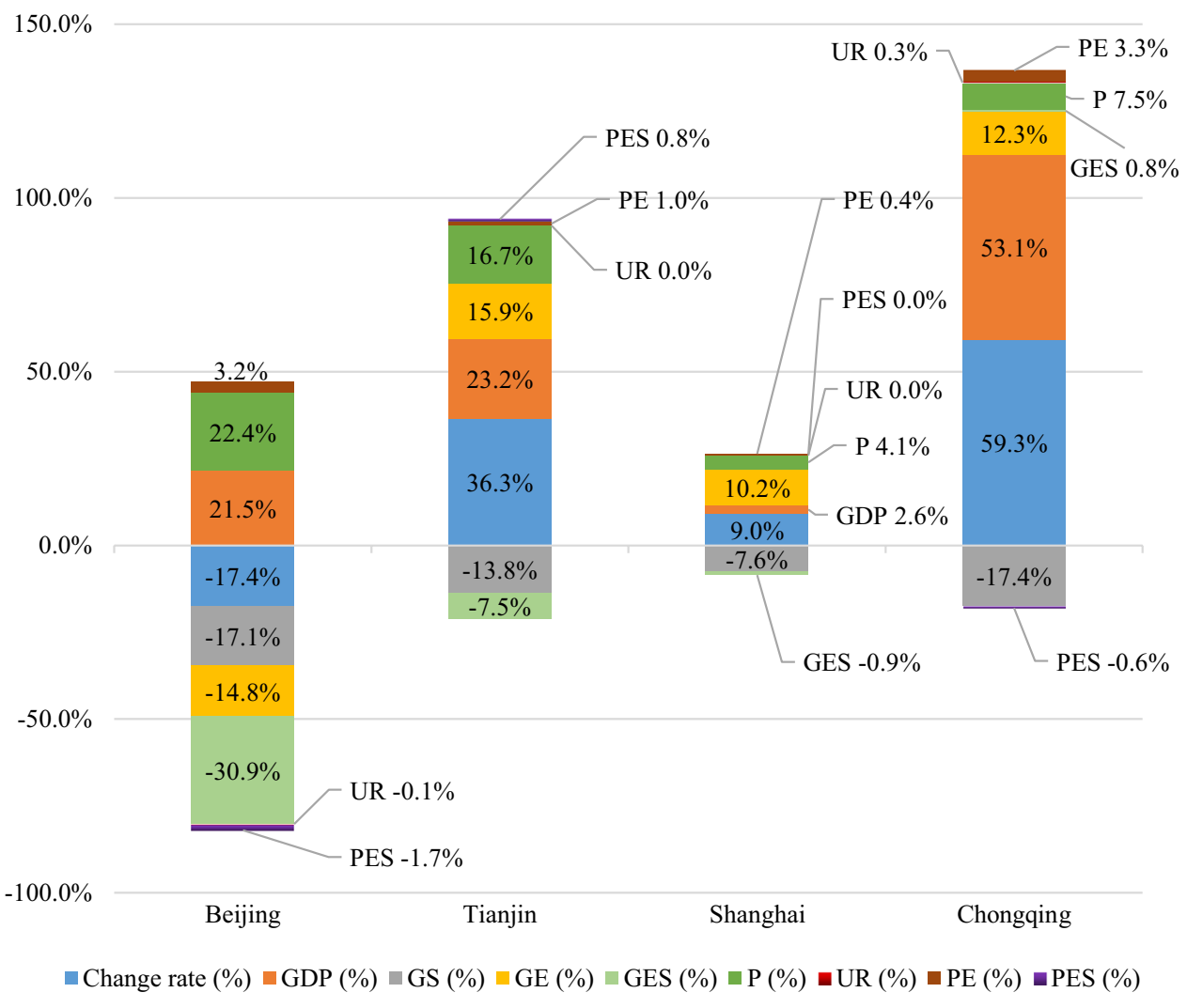

\section{Analysis of the driving factors of carbon emissions in different municipalities from 2007 to 2017}

Changes in carbon emissions vary considerably among municipalities. As shown in Figure 3, during 2007-2017, Beijing, Tianjin, Shanghai, and Chongqing changed by - $17.4 \%, 36.3 \%, 9.0 \%$, and $59.3 \%$ respectively. Only Beijing's carbon emissions changed negatively, falling by $17.4 \%$, while the remaining municipalities' carbon emissions rose in varying degrees, with Chongqing having the highest increase by $59.3 \%$.

In the above, driving factors of carbon emissions are divided into many aspects, such as GDP effect, industrial structure effect, and energy intensity effect. The data show that all factors have different effects on carbon emissions at the provincial level.

Economic development is the most important factor driving the growth of carbon emissions. Except for Chongqing, the positive contribution of economic growth to the growth of carbon emissions in the other three municipalities is no more than 50\%: Beijing (21.5\%), Tianjin (23.2 $\%)$, and Shanghai $(2.6 \%)$. This is because Chongqing's industry and manufacturing are well developed and the rapid economic development contributes to the growth of carbon emissions. What's more, the continuous expansion of the tertiary industry in recent years has ensured a relatively rapid GDP growth. In contrast, Shanghai's economy is already at the forefront in the country with a slowing GDP growth, which contributes less to carbon emission changes. Therefore, economic growth directly affects carbon emission growth. This result is consistent with the conclusion of (Jiang et al. 2017; Jia et al. 2018; Shen et al. 2018; Li and Qin 2019; Liao et al. 2019; He et al. 2020). To meet the high energy demand of industry, urbanization and transportation in developing countries, economic growth has made a great contribution to carbon emissions. However, different voices have emerged that carbon emissions have nothing to do with economic growth in developed countries and there is less evidence of dependence between energy consumption and economic growth (Waheed et al. 2019; Saidi and Mbarek 2016; Cai et al. 2018).

The industrial structure effect contributed negatively to the growth of carbon emissions in the four municipalities: Beijing (-17.1\%), Tianjin (-13.8\%), Shanghai $(-7.6 \%)$, and Chongqing (-17.4\%). Since "adjustment of industrial structure and transformation of economic growth pattern" was listed as the strategic priority and the main task in the Eleventh Five-Year Plan, China's industrial structure has been gradually adjusted and optimized in the decade. Under the guidance of new development concepts and supply-side structural reform, China has reversed the traditional extensive growth pattern. In the process of economic growth, the proportion of the secondary industry has decreased while that of the tertiary industry has continued to rise, as shown 
Fig. 4 Changes in the proportion of the secondary industry in each municipality from 2007 to 2017


Fig. 5 Changes in GDP energy intensity of each municipality from 2007 to 2017 in Figure 4. Thus, the reduction of dependence on industrial development will lead to a reduction in carbon emissions. Beijing achieved energy saving and emission reduction targets through adjusting its industrial structure (Mi et al. 2015), and the development of high-tech manufacturing with relatively lower carbon emissions in Chongqing was upward and rapid than the other cities (Tian et al. 2019). The transformation and upgrading of the industrial structure in Beijing and Chongqing have made the effect more negative than that in Tianjin and Shanghai.

While proposing the policy of industrial restructuring, China also set the goal of reducing energy intensity: by 2010 , energy consumption per unit of GDP should be reduced by $20 \%$ compared with 2005 , and by 2015 , be reduced by $16 \%$ compared with 2010. Changes in energy intensity of GDP in each municipality during 2007-2017 are shown in Figure 5.

Of the four municipalities, only in Beijing, a negative contribution, $-14.8 \%$, is seen in terms of contribution of energy intensity effect to the growth of carbon emissions, while in the other three municipalities, the effect has a positive contribution to carbon emission growth, including Tianjin (15.9\%), Shanghai (10.2\%), and Chongqing (12.3\%).
This result is different from the findings of other studies. For example, Zhang et al. (2016) find that energy intensity is the significant driver for the decrease of carbon intensity. The energy intensity effect of each municipality is the sum of the energy intensity effect of different sectors, among which, the effect of the industry sector plays a leading role whether being positive or negative. The change of energy intensity in Beijing shows that the Beijing Municipal Government attaches great importance to energy intensity and is taking active measures to maintain this index. The energy intensity reduction lies not only in the optimization of industrial structure but also in the improvement of energy efficiency in the secondary industry. In contrast, with the improvement of the technical level of the secondary industry, the rapid growth in energy consumption of the other three municipalities did not appear synchronously when China's GDP increased rapidly.

However, some of the negative effects of increased energy intensity were offset by the cleanliness of energy consumption structures, such as Beijing $(-30.9 \%)$, Tianjin $(-7.5$ $\%)$, and Shanghai $(-0.9 \%)$. The weakening effect of energy structure effect on carbon emission growth is greatly affected by renewable energy sources, which are used for end-use 
Fig. 6 Changes in the proportion of fossil energy in each municipality from 2007 to 2017

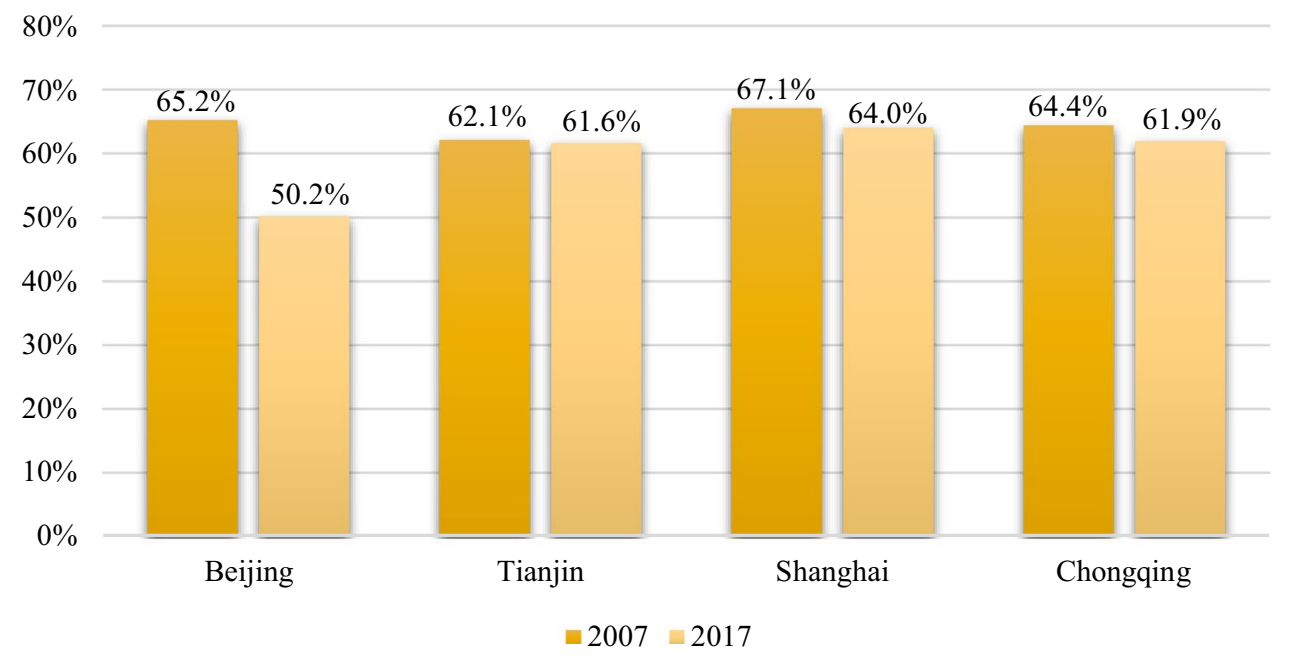

energy consumption in the form of one-off electricity, reducing the dependence on fossil energy and making the energy structure cleaner. As shown in Figure 6, the proportion of fossil energy decreased in different degrees in each municipality from 2007 to 2017. Beijing and Tianjin, though relatively scarce in renewable energy resources, receive electricity from neighboring provinces, which can be regarded as clean energy locally and has a more obvious inhibitory effect on the growth of carbon emissions. In 2017, Beijing purchased 67.3 billion $\mathrm{kWh}$ of electricity from other regions; this electricity accounts for $63.1 \%$ of its total electricity consumption (China Electric Power Yearbook 2018).

From the residential side, the population effect promoted carbon emissions in these four municipalities: Beijing (22.4 $\%)$, Tianjin (16.7\%), Shanghai (4.1\%), and Chongqing (7.5 $\%)$. Except for Beijing, this effect on carbon emissions is weaker than the GDP effect. Urbanization effect and energy structure effect have only a weak, even no influence on each municipality, but the per capita energy consumption effect has a positive effect on carbon emissions.

From 2007 to 2017, carbon emissions grew rapidly with the economic growth and rapid development of industrialization and urbanization. Among them, the GDP effect is the main driving factor to promote carbon emissions and has the greatest influence on carbon emissions. In addition, the effect of energy intensity, population effect, and per capita energy consumption effect all have obvious positive effects on carbon emission growth, while the industrial structure effect and energy structure effect have inhibitory effects on carbon emissions. Under the guidance of national policies, the trend towards energy conservation and consumption reduction, as well as industrial structure transformation and upgrading, has become more obvious, which has effectively suppressed the growth of carbon emissions caused by economic development and population growth. Because of its unique political status and high priority to the implementation of policies, Beijing has seen an overall decline of carbon emissions and a weakened contribution of energy intensity to carbon emissions growth. Therefore, the following analysis will focus on the effects of various factors in Beijing.

\section{Impact of urban development on carbon emissions}

The analysis shows that changes in urban carbon emissions are closely related to various driving factors, with GDP growth being the main one on the economic side and population growth on the residential side. From 2007 to 2017, GDP in Beijing, Tianjin, Shanghai, and Chongqing has increased by $185 \%, 253 \%, 145 \%$, and $315 \%$ respectively, and the permanent resident population increased by $29.53 \%, 39.64 \%$, $17.15 \%$, and $9.2 \%$ respectively. Economic and population growth contributed to carbon emissions by $43.9 \%, 39.9 \%$, $6.7 \%$, and $60.6 \%$ respectively. In addition, the economic side industry structure and energy intensity contribution rate also occupied a large proportion, while on the residential side, except for the population effect, which has an obvious effect, the per capita energy consumption effect in Tianjin and Shanghai is characterized by slow growth and has little impact on overall carbon emissions.

Over the past decade, GDP growth has been the primary target of each municipality, and the achievement of this economic target has inevitably led to a rapid increase in carbon emissions. Industrial development is the main driving force of GDP growth and the key factor that determines changes in carbon emissions among provinces in China. The Chinese government has attached great importance to energy conservation and has put forward clear reduction targets of energy consumption per unit of GDP in many five-year plans. Since the Eleventh Five-Year Plan, it has become a binding index. Therefore, accelerating economic transformation and strengthening policy implementation mechanisms 
are important measures to strengthen the inhibitory effect of industrial structure effect and energy intensity effect on carbon emission growth.

The development of Beijing in this decade shows that economic growth has inevitably brought a considerable increase in carbon emissions (Cui et al. 2020). However, since 1995, the proportion of the secondary industry in Beijing has been declining continuously from $23.68 \%$ in 1995 to $19.26 \%$ in 2016 . The proportion of the tertiary industry continued to rise from $52.52 \%$ in 1995 to $80.23 \%$ in 2016 . The cleanness of the industrial structure has effectively promoted the economic transformation of Beijing. In 2005, the seventh edition of Beijing City Master Plan (2004-2020) continued the urban development strategy of the fifth edition of Beijing City Construction Master Plan (Draft) that "heavy industry is no longer developing basically," and proposed that the economic center gradually fade out of Beijing's core development goals. This created more room for the development of high-precision industries, and the industrial structure effect became an important driving factor to restrain the growth of carbon emissions in Beijing.

During the periods of the Eleventh Five-Year Plan and Twelfth Five-Year Plan, under the clear requirements of reduction in the energy consumption per unit of GDP, the Beijing Municipal Government took active measures to control this indicator through saving energy and diminishing energy consumption, which reduced energy intensity and carbon emissions when the industrial energy consumption intensity of the other three cities was relatively high. At the same time, under the coal control policy, Beijing's energy structure has undergone major changes with a continuous decline of both quantity and proportion of coal and a continuous growth of natural gas share. The trend of decarbonization of the energy structure is so obvious that carbon emissions begin to fall (Guo and Meng 2019).

Compared with industry, the carbon emissions related to people's livings are more complex and closely related to the consumption behaviors of residents. Carbon emission in consumption areas such as transportation is becoming an important factor limiting the continuous decline of carbon emissions. Due to the increase of permanent population and promotion of urbanization in Beijing, the carbon emissions in construction and transportation are increasing continuously, which makes the per capita energy consumption effect positively promote carbon emissions.

\section{Conclusions and policy implications}

\section{Conclusion}

As the largest developing country, China is also the largest energy consumer and carbon emitter in the world and its carbon emission reduction is important not only for domestic economic transformation but also for achieving global climate goals. Therefore, China has proposed a series of goals and policies, which directly or indirectly affect the growth of carbon emissions. Based on the data of four representative municipalities, namely Beijing, Tianjin, Shanghai, and Chongqing from 2007 to 2017, this paper discusses the contribution of each driving factor to carbon emissions by using the LMDI decomposition method. Starting from the city level, the driving factors of energy-related $\mathrm{CO} 2$ emission in Chinese megacities are uncovered. Other cities in China and even other countries around the world can draw on the experiences of municipalities to identify the main driving factors of carbon emissions and better design the roadmap of carbon emission reduction. The municipality itself should also try to give full play to its innate advantages and lead the construction of low-carbon clean cities. The analysis of the driving factors of carbon emissions in municipalities shows that at the municipality level, the driving factors of carbon emission growth are GDP effect and population effect, and in municipalities with fast economic growth, the most important driving factor is GDP effect; the driving factors that inhibit the growth of carbon emissions include industrial structure effect and energy structure effect, with the former being dominant. However, these factors are not identical in the degree of influence of each municipality, which varies greatly because of the economic growth rate, urban planning, and policy focus of each municipality, especially Beijing.

\section{Policy implications}

The conclusion shows that the main driving forces for China's low-carbon transition include developing high-tech industries, adhering to the concept of energy conservation, making efforts to increase the proportion of clean energy sources such as wind energy and nuclear energy, building a clean energy-based supply system and consumption structure, and adopting advanced science and technology as well as policy plans to reduce energy consumption and carbon emission intensity while striving to promote economic development. Therefore, China's economic policy should focus on the following:

(1) Transforming development thoughts. It is undeniable that the GDP effect is still the most important driving factor of carbon emission growth. Under the high carbon path dominated by fossil energy, energy consumption will inevitably cause carbon dioxide emissions due to the development of the economy, which shows that the result of increasing carbon emissions caused by economic development is almost inevitable. To reduce the effect of economic development on car- 
bon emissions, we can change our mode of thinking, and choose a path that is more in line with the actual situation. While promoting economic development, we can reduce the growth rate of carbon emissions and keep long-term carbon emissions decline through other efforts.

(2) Optimizing the industrial structure. There are great differences in the industrial structures in different regions of China. To change the existing high carbon industrial structure, we should adopt different policies in different regions and guide the flow of capital to the optimization of industrial structure. In addition, we should vigorously develop advanced manufacturing, high-end service industries, and high-tech industries, foster strategic emerging industries, and increase the proportion of tertiary industries in the national economy while reducing the proportion of high-carbon industries so that the industrial structure effect can play a greater role in economic growth and low carbonization (Ma et al. 2019).

(3) Adjusting energy structure. Although the energy structure effect is not the main driving factor to restrain the increase of carbon emissions, it still contributes to the reduction of carbon emissions in China, indicating that optimizing energy structure is also an effective measure to restrain the increase of carbon emissions. Therefore, clean coal should be used more to replace raw coal, and clean energy such as hydro energy, nuclear energy, wind energy, solar energy, and bioenergy should be developed to reduce the proportion of coal and oil in China's energy consumption, thus reducing China's carbon emissions.

(4) Innovating technologies to reduce emissions (Yang et al. 2020b). While determined path and method of emission reduction are important, energy-saving and emission reduction technologies are key factors to determine whether emission reduction is effective. We should take active measures to introduce funds, and encourage innovative progress in technologies for renewable energy development and for the clean and efficient use of coal to further improve energy utilization and energy efficiency. Furthermore, we should develop energy conservation technologies, and implement the mechanism of clean and sustainable development.

It should be noted that although this study reveals the important driving factors regarding carbon emissions in megacities of developing countries by using LMDI based on the extended kaya identity, several limitations remain. For instance, in addition to other large cities in China and other countries, the findings of this paper may be difficult to apply to the small cities or county level. In addition, further decomposition could be achieved by integrating various useful ecological indicators, such as the decoupling index. We intend to address these limitations in future studies.

Acknowledgements The authors would like to acknowledge great thanks to anonymous reviewers for their valuable comments which largely improve the academic quality of this paper. The usual caveats apply.

Author contribution Yajing Jiang: Formal analysis, data curation and writing - original draft; Yuanxin Liu: Writing - review \& editing; Jiahai Yuan: Conceptualization, methodology and project administration; Hui Liu: Supervision; Bo Li: Supervision.

Funding The paper is supported by the funding of the Social Science Foundation of Beijing Municipality (20JCC085), the National Natural Science Foundation of China (72173043) and 111 Project (B18021).

Data availability The datasets used and/or analyzed during the current study are available from the corresponding author on reasonable request.

\section{Declarations}

Ethics approval and consent to participate Not applicable.

Consent for publication Not applicable.

Competing interests The authors declare no competing interests.

\section{References}

Akbostancı E, Tunç Gİ, Türüt-Aşık S (2011) CO2 emissions of Turkish manufacturing industry: a decomposition analysis. Appl Energy 88:2273-2278

Ang BW (2004) Decomposition analysis for policymaking in energy. Energy Policy 32:1131-1139

Ang BW, Choi KH (1997) Decomposition of aggregate energy and gas emission intensities for industry: a refined Divisia index method. Energy J 18(3):59-73

Cai Y, Sam CY, Chang T (2018) Nexus between clean energy consumption, economic growth and $\mathrm{CO} 2$ emissions. J Clean Prod 182:1001-1011

Cansino JM, Román R, Ordóñez M (2016) Main drivers of changes in $\mathrm{CO} 2$ emissions in the Spanish economy: a structural decomposition analysis. Energy Policy 89:150-159

Chen J, Xu C, Cui L, Huang S, Song M (2019) Driving factors of $\mathrm{CO} 2$ emissions and inequality characteristics in China: a combined decomposition approach. Energy Econ 78:589-597

China Electric Power Yearbook (2018) China Electric Power Press, Beijing

Cui G, Yu Y, Zhou L, Zhang H (2020) Driving forces for carbon emissions changes in Beijing and the role of green power. Sci Total Environ 728:138688

Das A, Paul SK (2014) CO2 emissions from household consumption in India between 1993-94 and 2006-07: a decomposition analysis. Energy Econ 41:90-105

Gao C, Ge H (2020) Spatiotemporal characteristics of China's carbon emissions and driving forces: a five-year plan perspective from 2001 to 2015. J Clean Prod 248:119280 
Gao C, Liu Y, Jin J, Wei T, Zhang J, Zhu L (2016) Driving forces in energy-related carbon dioxide emissions in east and south coastal China: commonality and variations. J Clean Prod 135:240-250

Guan D, Hubacek K, Weber CL, Peters GP, Reiner DM (2008) The drivers of Chinese CO2 emissions from 1980 to 2030. Glob Environ Chang 18:626-634

Guo M, Meng J (2019) Exploring the driving factors of carbon dioxide emission from transport sector in Beijing-Tianjin-Hebei region. $\mathrm{J}$ Clean Prod 226:692-705

He J, Yue Q, Li Y, Zhao F, Wang H (2020) Driving force analysis of carbon emissions in China's building industry: 2000-2015. Sustain Cities Soc 60:102268

Jeong K, Kim S (2013) LMDI decomposition analysis of greenhouse gas emissions in the Korean manufacturing sector. Energy Policy 62:1245-1253

Jia J, Gong Z, Xie D, Chen J, Chen C (2018) Analysis of drivers and policy implications of carbon dioxide emissions of industrial energy consumption in an underdeveloped city: The case of Nanchang, China. J Clean Prod 183:843-857

Jiang J, Ye B, Xie D, Tang J (2017) Provincial-level carbon emission drivers and emission reduction strategies in China: combining multilayer LMDI decomposition with hierarchical clustering. J Clean Prod 169:178-190

Li H, Qin Q (2019) Challenges for China's carbon emissions peaking in 2030: a decomposition and decoupling analysis. J Clean Prod 207:857-865

Li R, Wang Q, Liu Y, Jiang R (2021) Per-capita carbon emissions in 147 countries: the effect of economic, energy, social, and trade structural changes. Sustaina Prod Consum 27:1149-1164

Liao C, Wang S, Fang J, Zheng H, Liu J, Zhang Y (2019) Driving forces of provincial-level $\mathrm{CO} 2$ emissions in China's power sector based on LMDI method. Energy Procedia 158:3859-3864

Ma X, Wang C, Dong B, Gu G, Chen R, Li Y, Zou H, Zhang W, Li Q (2019) Carbon emissions from energy consumption in China: its measurement and driving factors. Sci Total Environ 648:1411-1420

Mi Z, Pan S, Yu H, Wei Y (2015) Potential impacts of industrial structure on energy consumption and $\mathrm{CO} 2$ emission: a case study of Beijing. J Clean Prod 103:455-462

National Bureau Of Statistics (2020) National Development Statistics of China, Beijing

Saidi K, Mbarek MB (2016) Nuclear energy, renewable energy, CO2 emissions, and economic growth for nine developed countries: evidence from panel Granger causality tests. Prog Nucl Energy 88:364-374

Shan Y, Huang Q, Guan D, Klaus H (2020) China CO2 emission accounts 2016-2017. Scientific Data 7

Shen L, Wu Y, Lou Y, Zeng D, Shuai C, Song X (2018) What drives the carbon emission in the Chinese cities? - a case of pilot low carbon city of Beijing. J Clean Prod 174:343-354

Sun W, Huang C (2020) How does urbanization affect carbon emission efficiency? Evidence from China. J Clean Prod 272:122828

Sun W, Ren C (2021) The impact of energy consumption structure on China's carbon emissions: taking the Shannon-Wiener index as a new indicator. Energy Rep 7:2605-2614

Tian X, Bai F, Jia J, Liu Y, Shi F (2019) Realizing low-carbon development in a developing and industrializing region: impacts of industrial structure change on $\mathrm{CO} 2$ emissions in southwest China. J Environ Manag 233:728-738

Waheed R, Sarwar S, Wei C (2019) The survey of economic growth, energy consumption and carbon emission. Energy Rep 5:1103-1115

Wang Q, Jiang R (2019) Is China's economic growth decoupled from carbon emissions? J Clean Prod 225:1194-1208
Wang Q, Su M (2020) Drivers of decoupling economic growth from carbon emission-an empirical analysis of 192 countries using decoupling model and decomposition method. Environ Impact Assess Rev $81: 106356$

Wang Q, Wang S (2020) Preventing carbon emission retaliatory rebound post-COVID-19 requires expanding free trade and improving energy efficiency. Sci Total Environ 746:141158

Wang H, Ang BW, Su B (2017) Assessing drivers of economy-wide energy use and emissions: IDA versus SDA. Energy Policy 107:585-599

Wang Q, Zhao M, Li R, Su M (2018) Decomposition and decoupling analysis of carbon emissions from economic growth: a comparative study of China and the United States. J Clean Prod 197:178-184

Wang Q, Zhao M, Li R (2019) Decoupling sectoral economic output from carbon emissions on city level: a comparative study of Beijing and Shanghai, China. J Clean Prod 209:126-133

Wang F, Sun X, Reiner DM, Wu M (2020) Changing trends of the elasticity of China's carbon emission intensity to industry structure and energy efficiency. Energy Econ 86:104679

Wang Q, Wang S, Jiang X (2021) Preventing a rebound in carbon intensity post-COVID-19-lessons learned from the change in carbon intensity before and after the 2008 financial crisis. Sustainable Production and Consumption 27:1841-1856

Wei J, Huang K, Yang S, Li Y, Hu T, Zhang Y (2017) Driving forces analysis of energy-related carbon dioxide (CO2) emissions in Beijing: an input-output structural decomposition analysis. J Clean Prod 163:58-68

Wu Y, Shen L, Shuai C, Jiao L, Liao S, Guo Z (2021) Key driving forces on the development of low carbon city (LCC) in China. Ecol Indic 124:107379

Xia C, Wang Z, Xia Y (2021) The drivers of China's national and regional energy consumption structure under environmental regulation. J Clean Prod 285:124913

Xu S, He Z, Long R (2014) Factors that influence carbon emissions due to energy consumption in China: decomposition analysis using LMDI. Appl Energy 127:182-193

Xu S, Zhang L, Liu Y, Zhang W, He Z, Long R, Chen H (2017) Determination of the factors that influence increments in $\mathrm{CO} 2$ emissions in Jiangsu, China using the SDA method. J Clean Prod 142:3061-3074

Xu L, Du H, Zhang X (2021) Driving forces of carbon dioxide emissions in China's cities: an empirical analysis based on the geodetector method. J Clean Prod 287:125169

Yang J, Cai W, Ma M, Li L, Liu C (2020) Driving forces of China's CO2 emissions from energy consumption based on Kaya-LMDI methods. Sci Total Environ 711:134569

Yang M, Hou Y, Fang C, Duan H (2020b) Constructing energy-consuming right trading system for China's manufacturing industry in 2025. Energy Policy 144:111602

Ye B, Jiang J, Li C, Miao L, Tang J (2017) Quantification and driving force analysis of provincial-level carbon emissions in China. Appl Energy 198:223-238

Yuan J (2018) The future of coal in China. Resour Conserv Recycl 129:290-292

Zhang W, Li K, Zhou D, Zhang W, Gao H (2016) Decomposition of intensity of energy-related $\mathrm{CO} 2$ emission in Chinese provinces using the LMDI method. Energy Policy 92:369-381

Zhao M, Tan L, Zhang W, Ji M, Liu Y, Yu L (2010) Decomposing the influencing factors of industrial carbon emissions in Shanghai using the LMDI method. Energy 35:2505-2510

Publisher's note Springer Nature remains neutral with regard to jurisdictional claims in published maps and institutional affiliations. 